\section{Prognosis for diagnosis}

Philip Mortimer

HIV Detection by Genetic Engineering

Methods. Edited by Paul A. Luciw and Kathelyn Sue Steimer. Marcel Dekker: 1989. Pp. 301. \$99. 75 (North America); $\$ 119.50$ (elsewhere).

ANYONE who doubts the scope and power of modern biotechnology should look through this book. It shows how, from a standing start in 1984, academic and commercial laboratories in the United States have raised HIV diagnostics from crude art to high science.

A cursory inspection of the contents reveals how busy the research and development laboratories have been and how remarkable their achievements. A more attentive read, even by a beginner, would lead to a broad understanding of the techniques of antibody testing, antigen detection, in situ hybridization and gene amplification as they are being applied to HIV diagnosis. The various authors have placed genetic engineering in the broad context of laboratory diagnosis, and the book illustrates very well how the new approaches are interacting with the old. What is being so rapidly achieved for HIV will very soon be applied in other diagnostic areas and, as the final chapter on HTLV I suggests, this process has already begun. Diagnostic tests will become safer, cheaper, more accurate, more discriminating and more versatile.

The popular conception of genetic engineering is that it will revolutionize therapeutics and immunization: the reality is that diagnostics will be transformed first. Existing tests will be refined and (as has recently been shown for non- $A$ non-B hepatitis) new diagnoses offered. The work on HIV exemplifies this process and here is a volume that conveniently records what is happening. The book will have a short shelf life, but it is an important and thoroughly worthwhile read.

Philip Mortimer is Director of the PHLS Virus Reference Laboratory, Central Public Health Laboratory, Colindale Avenue, London NW9 5HT, UK.

\section{On coherence}

\author{
G. H. C. New
}

Lasers. By Peter W. Milonni and Joseph H. Eberly. Wiley:1988. Pp.731. £35.85, $\$ 49.95$.

IN RAPIDLY developing areas of research, it is only to be expected that textbooks will be few and far between. The people who, in less frenetic times, would be writing them, instead burn the midnight oil in their laboratories. Laser physics is a good example. In barely 30 years, it has grown from nothing into a vast field of endeavour that now impinges on innumerable aspects of science and technology. And although there are a few excellent books on the subject, lecturers giving courses on lasers know only too well how difficult it often is to find a suitable text for their students.

Milonni and Eberly's new book will solve the problem for some people; as a supporting text for an introductory course at the first-year graduate level, it is ideal. The strength of the book lies in its breadth rather than its depth, for the authors' intention is to describe the broad foundations of the subject rather than taking readers into uncharted territory.

Following an elementary introduction to lasers, there are eight chapters concerned with basic radiation theory. All the topics one would expect are covered, including classical dispersion and absorption theory, the Einstein A and B coefficients, the Schrödinger, Maxwell and

\section{From Noah on}

\section{Hugh Torrens}

Catastrophic Episodes in Earth History. By Claude C. Albritton, Jr. Chapman \& Hall: 1989. Pp.221. Hbk £27.50, $\$ 29.95$; pbk £12.95.

THE subject tackled in Claude Albritton's book is a minefield, one made all the more dangerous by the recent 'catastrophe' of judging scholarship by volume. Albritton starts with an historical survey of disaster and catastrophe from Noah to now from the Flood, to Werner's German neptunism or Hutton's Scottish plutonism, and beyond. We learn that Werner's lectures drew "hundreds of students from all over Europe", but are not told that far more were attracted to Edinburgh from all over the world. Moreover, students in Edinburgh were not indoctrinated, but could make up their own minds.

The new catastrophism of meteorite impacts, and the 'resulting' mass extinctions and other catastrophe scenarios, are discussed next. Here is a lucid, up-to-date survey of these heated issues, aimed at undergraduates and the many others who are equally bewildered. Because it is wellnigh impossible to write an historical account of such a continuing debate, however, these sections are less satisfactory as history. (I wish historians would notice the existence of Rene Gallant's Bombarded Earth: An Essay on the Geological and Biological Effects of Huge Meteorite Impacts; that book was published in 1964, years before the advent of the Alvarez hypothesis of mass extinctions.)

Albritton finally puts the new catastrophism into proper perspective and explains recent ideas which led to it and to dinosaurmania. He takes a sensible, on the fence, stance as to possible causes of mass extinction. One problem in the debate has been the lack of quantification of 'catastrophes'. A Yorkshire vicar, arguing with Lyell in the 1840 s, postulated gradual rates of local sedimentary deposition - but at 900 feet $(275 \mathrm{~m})$ a month! Only in a British climate could one see such rates as non-catastrophic; thus my review copy arrived during a snow storm after one of the mildest European winters on record. The same day I learnt of Claude Albritton's death and we must mourn a true interdisciplinarian. His last book provides a fitting requiem.

Hugh Torrens is a Senior Lecturer in the Department of Geology, University of Keele, Staffordshire ST5 5BG, UK.

- Thoughts on a different sort of catastrophe are the subject of Spencer R. Weart's Nuclear Fear: A History of Images. The book, now in paperback, was reviewed in Nature 335, 775 (1988). Publisher is Harvard University Press, price is $\$ 14.95$, $£ 11.95$. 